\title{
CD8 cytotoxic T-cell clone rapidly transfers autoimmune diabetes in very young NOD and MHC class I-compatible scid mice
}

\author{
R . Yoneda, K. Yokono, M . N agata, Y. Tominaga, H . M oriyama, K. T sukamoto, M . M iki, N . 0 kamoto, H . Yasuda, \\ K. A mano, M. Kasuga
}

Second Department of Internal Medicine, Kobe University School of Medicine, Kobe, Japan

Summary A CD8 T-cell clone (YNK1.3) generated from acutely diabetic NOD mouse islets, showed proliferation and cytotoxicity when challenged with NOD and BALB/c islet cells and NOD-derived insulinoma cells. When $1-2 \times 10^{7}$ YNK1.3 cells were administered to 7-10-day-old NOD mice, the cells transferred overt diabetes very rapidly in each of the 16 recipients within 4 days of cell transfer. However, of 14 recipients receiving YNK 1.3 cells above 14 days of age none became diabetic. Fluorescent dye-labelled YNK1.3 cells extensively accumulated in the islets by $36 \mathrm{~h}$ after transfer in 7-day-old NOD recipients, while no significant insulitis was seen in 21-day-old recipients. Over half of NOD-scid recipients $(5 / 9)$ rapidly became diabetic within 5 days after transfer of 1-2 $210^{7}$ YNK1.3 cells at 7 days of age, whereas only one of 12 recipients over 14 days of age became diabetic. Furthermore, YNK1.3 cells also transferred diabetes to $\mathrm{H}-2 \mathrm{~K}^{\mathrm{d}}$-matched very young
$\mathrm{BALB} / \mathrm{c}$-scid and $\mathrm{CB} 17$-scid mice, but not to C57BL/6-scid mice. Thus, optimally activated isletspecific CD8 T-cell clones are able to rapidly transfer diabetes to NOD and MHC class I compatible scid mice when a large enough number is administered at 7 days of age. Administration of monoclonal antibodies against adhesion molecules involved in the trafficking of lymphocytes from the circulation into the inflammatory tissues, could not prevent the cellular infiltration of YNK1.3 cells into the islets in 7-dayold NOD recipients. The results indicate that islet cells in the mouse around 7 days of age are generally susceptible to cytotoxic CD8 T cells, suggesting, therefore, that $\mathrm{CD} 8 \mathrm{~T}$ cells may play an important role in the initiation of autoimmune diabetes in NOD mice. [Diabetologia (1997) 40: 1044-1052]

Keywords CD8 T-cell clone, NOD mice, scid mice, transfer of diabetes, insulitis, adhesion molecule.
Nonobese diabetic (NOD) mice spontaneously develop an autoimmune diabetes resembling human

Received: 18 February 1997 and in revised form: 29 April 1997

Corresponding author: K. Yokono, M.D., Ph.D., Second Department of Internal Medicine, Kobe University School of Medicine, 7-5-1 Kusunoki-cho, Chuo-ku, Kobe 650, Japan A bbreviations: NOD, Nonobese diabetic; IDDM, insulin-dependent diabetes mellitus; scid, severe combined immunodeficient; APC, antigen-presenting cell; IL, interleukin; MMC, mitomycin $\mathrm{C}$; mAb, monoclonal antibody; FCS, fetal calf serum;.VCAM-1, vascular cell adhesion molecule-1; ICAM-1, intercellular adhesion molecule-1; LFA-1, leukocyte functionassociated antigen-1; IFN, interferon; VLA-4, very late antigen-4; CTL, cytotoxic T lymphocytes; GABA, $\gamma$-aminobutyric acid. insulin-dependent diabetes mellitus (IDDM). Several lines of evidence suggest that $\mathrm{T}$ cells are responsible for mononuclear cell infiltration into the islets (insulitis) and destruction of beta cells in NOD mice. Disease transfer studies have shown that both splenic CD4 and CD8 T cells from diabetic NOD mice are necessary to transfer diabetes to newborn or sublethally irradiated NOD mice $[1,2]$ and islet-specific CD4 and CD8 T-cell clones are both required before significant insulitis develops in irradiated NOD mice [3]. However, islet-specific CD4 T-cell clones have been found to cause diabetes when injected into unmanipulated young NOD mice [4] or NOD F1 mice [5]. In addition, CD4 T cells from diabetic NOD donors have also been shown to transfer disease into NOD-severe combined immunodeficient (scid) mice 
in which normal development of functional lymphocytes is prevented [6]. These findings may indicate that CD4 T cells are essential for development of diabetes, because they play an important role in disease initiation and they activate and recruit CD8 T cells as the final effector in the destruction of beta cells in NOD mice. However, in order to induce CD4 T cellmediated autoimmunity against beta cells, putative autoantigen(s) must be released from the beta cells, processed and presented by the antigen-presenting cells (APC). The important role of CD8 T cells in the initiation of autoimmune diabetes has been supported by recent observations that $\beta 2$-microglobulindeficient NOD mice developed neither insulitis nor diabetes [7, 8], and CD8 T-cell clones from young NOD islets could rapidly transfer diabetes in irradiated NOD and NOD-scid mice in the absence of CD4 T cells [9].

In the present study, we established an optimally activated $\mathrm{H}-2 \mathrm{~K}^{\mathrm{d}}$-restricted $\mathrm{CD} 8$ cytotoxic T-cell clone from NOD islets using different procedures from other islet-specific CD8 T-cell clones previously reported $[9,10]$. Using this CD8 T-cell clone, we tried to transfer diabetes into NOD and several scid mice under various conditions by changing the number of donor cells and the age of recipients.

\section{Materials and methods}

M ice. NOD/Shi/Kbe mice were maintained in the Institute for Experimental Animals, Kobe University School of Medicine. The original colony was kindly supplied by Aburahi Laboratories (Shionogi Research Institute, Shiga, Japan). In our colony, insulitis becomes noticeable in most mice at 4-6 weeks of age, and the incidence of insulitis increases with age and reaches $95-100 \%$ in both sexes at 20 weeks of age. The cumulative incidence of diabetes at 30 weeks of age was 65 and $5 \%$ for female and male NOD mice, respectively. NOD-scid, BALB/cscid, CB17-scid, and C57BL/6-scid mice were a kind gift of Dr. K. Hioki (The Central Institute of Experimental Animals, Kawasaki, Japan). All animals were maintained in a filtered air environment and fed with autoclaved water and food. Various scid mice were treated with a sulfamethoxazole/trimethoprim mixture (Shionogi, Tokyo, Japan) in drinking water for 3 days per week to prevent infection by pneumocystis carinii.

G eneration of islet-specific CD 8 T-cell clones. CD8 T-cell lines were generated from lymphocytes infiltrating islets from 20week-old acutely diabetic female NOD mice. Isolated islets were cultured with RPMI 1640 medium including $1 \%$ syngenic serum and $0.5 \mathrm{U} / \mathrm{ml}$ recombinant interleukin-2 (rIL-2) (kindly provided by Takeda Pharmaceutical Inc., Osaka, Japan). After 7 days' culture, $1 \times 10^{4}$ proliferated lymphocytes were restimulated with 20-30 mitomycin C (MMC)-treated NOD islets and $2 \times 10^{5}$ MMC-treated NOD spleen cells in $200 \mu \mathrm{l}$ IL-2free RPMI 1640 medium in each well of round bottomed 96well microculture plates (Corning Coster Co., Cambridge, Mass., USA). After 2 days' stimulation, rIL-2 was added to the wells in a final concentration of $0.5 \mathrm{U} / \mathrm{ml}$ to expand lymphocytes. Every 2 weeks, CD4 T cells were deleted from expanded lymphocytes using an anti-CD4 monoclonal antibody
(mAb) (GK1.5; ATCC, Rockville, MD., USA), and anti-rat IgG-conjugated magnetic beads (BioMag; Advanced Magnetic Inc., Cambridge, Mass., USA). After 2 to 3 cycles of restimulation, CD8 T-cell lines were cloned by limiting dilution. CD8 T cells were seeded at 1 cell per well in 96-well culture plates containing 10 MMC-treated NOD islets and $2 \times 10^{5}$ MMCtreated NOD spleen cells in RPMI 1640 medium supplemented with $10 \%$ fetal calf serum (FCS) and $0.5 \mathrm{U} / \mathrm{ml} \mathrm{rIL-2.} \mathrm{Cloned}$ lymphocytes were repeatedly stimulated and expanded by rIL2 and checked CD8 molecules by flow cytometric analysis. One CD8 T-cell clone (YNK1.3) was selected for this experiment because of its stable proliferation and higher cytotoxicity. Another CD8 T-cell clone (YNK2.1) which lost its cytotoxic activity for NOD islet cells and NOD-derived insulinoma cells during cell culture served as control.

Proliferation assay. Isolated islets from NOD $\left(\mathrm{H}-2 \mathrm{~K}^{\mathrm{d}} \mathrm{D}^{\mathrm{b}}\right)$, $\mathrm{BALB} / \mathrm{c}\left(\mathrm{H}-2^{\mathrm{d}}\right)$, and $\mathrm{C} 57 \mathrm{BL} / 6\left(\mathrm{H}-2^{\mathrm{b}}\right)$ mice and murine insulinoma cell lines, MIN6N8 a $\left(\mathrm{H}-2 \mathrm{~K}^{\mathrm{d}} \mathrm{D}^{\mathrm{b}}\right)$ and MIN6 $\left(\mathrm{H}-2^{\mathrm{b}}\right)$, were used as antigen. YNK1.3 cells $\left(1 \times 10^{4}\right)$ were cultured with 10 MMC-treated whole islets or $1 \times 10^{4}$ insulinoma cells in $200 \mu \mathrm{l}$ RPMI 1640 medium containing $10 \%$ FCS in 96-well U-bottomed culture plates. After $48 \mathrm{~h}$, rIL-2 was added to the wells (final concentration: $0.5 \mathrm{U} / \mathrm{ml}$ ). Cells were pulsed with $1 \mu \mathrm{Ci}$ ${ }^{3} \mathrm{H}$-thymidine per well for the final $16 \mathrm{~h}$ of a 4 -day culture. ${ }^{3} \mathrm{H}$ thymidine incorporation was measured by a liquid scintillation counter and data are expressed as the mean \pm SD of three different experiments.

Flow cytometry. YNK1.3 cells were stained by antibodies against various cell surface molecules; anti-CD25 (anti-IL-2 receptor, 7D4, ATCC), anti- $\alpha 4$-integrin (R1-2), anti-CD28, anti$\beta 7$-integrin, anti-CD69 (PharMingen, San Diego, Calif., USA), and anti-CD54 (KAT-1) mAbs [11]. FITC-conjugated antimouse IgM (Cappel, Westchester, Penn., USA) was used for anti-CD25, FITC-conjugated anti-hamster antibody (Cederlane, Homby, Ontario, Canada) for anti-CD28, and FITC-conjugated anti-rat IgG (Cappel) for anti- $\alpha 4$-integrin, anti- $\beta 7$-integrin, anti-CD69, and anti-CD54 mAbs. Cells $\left(1 \times 10^{6}\right)$ were incubated with $\mathrm{Ca}, \mathrm{Mg}$-free Hanks balanced salt solution with $1 \%$ FCS and $0.1 \%$ sodium azide for $30 \mathrm{~min}$ at $4{ }^{\circ} \mathrm{C}$ and subsequently incubated with relevant second antibodies in indirect staining. Fluorescence intensity was analysed on an FACS 440 flow cytometer (Becton Dickinson, San Jose, Calif., USA).

A doptive transfer of diabetes by CD 8 T-cell clones. Female NOD mice (7-28-day-old), NOD-scid mice (7-21-day-old), BALB/c-scid mice (7-14-day-old), CB17-scid mice (7-dayold), or C57BL/6-scid mice (7-day-old) were used in the adoptive transfer experiments. First, various numbers $\left(1 \times 10^{6}-\right.$ $2 \times 10^{7}$ ) of cloned CD8 T cells (YNK1.3) in $100 \mu$ l of sterile Hanks-balanced salt solution were injected intraperitoneally into 7-day-old NOD mice. As more than $1 \times 10^{7}$ YNK1.3 cells can induce diabetes within 7 days after transfer, $1 \times 10^{7}$ YNK1.3 cells were injected to NOD mice and scid mice at various ages. When $1 \times 10^{7} \mathrm{YNK} 1.3$ cells did not induce diabetes, $2-4 \times 10^{7}$ YNK1.3 cells were injected. Mice were monitored frequently for 42 days after transfer. Onset of diabetes was monitored by testing urinary glucose with Tes-Tape (Lilly, Indianapolis, Ind., USA) every day and was confirmed by higher plasma glucose concentrations ( $>16.7 \mathrm{mmol} / \mathrm{l}$ ) on 2 consecutive days. Pancreases of these mice were removed and their cryostat sections were stained with haematoxylin and eosin.

Preparation and administration of fluorescent dye-labelled YNK 1.3 cells. YNK1.3 cells were labelled with fluorescent dye, PKH2 (Zynaxis Cell Science, Inc., Malvern, Penn., USA) 
[12]. Seven-day-old female NOD mice were injected intraperitoneally with $1 \times 10^{7} \mathrm{PKH} 2$-labelled YNK1.3 cells. The mice were killed at $36 \mathrm{~h}$ post-transfer, and their pancreas, liver, spleen, and kidney were frozen in OCT compound (Miles, St. Louis, Mo., USA) in nitrogen liquid. Five $\mu \mathrm{m}$ frozen sections were mounted on albumin coated slides, dried in the dark, and then mounted with an antifade medium. The slides were examined for the presence of YNK1.3 cells under fluorescence microscopy.

Administration of anti-adhesion molecule mA bs to CD 8 T-cell clone-induced diabetes. Seven-day-old NOD mice were injected intraperitoneally with $500 \mu \mathrm{g}$ of either R1-2; anti- $\alpha 4$-integrin and $\mathrm{M} / \mathrm{K} 2$; anti-vascular cell adhesion molecule-1 (VCAM-1) mAbs [13] or KAT-1; anti-intercellular adhesion molecule-1 (ICAM-1) and KBA; anti-leukocyte function-associated antigen-1 (LFA-1) mAbs [14] at 1 day before transfer of YNK1.3 cells. Hybridoma cells secreting these mAbs (kindly provided by Dr. H. Yagita and Dr. K. Okumura, Juntendo University School of Medicine, Tokyo, Japan) were injected into nude mice, and mAbs harvested as ascites were purified though Protein A-sepharose column. Transferred YNK1.3 cells $\left(1 \times 10^{7}\right)$ were preincubated with $10 \mu \mathrm{g} / \mathrm{ml}$ relevant mAbs for $30 \mathrm{~min}$ at $4^{\circ} \mathrm{C}$ before injection into corresponding mAbspretreated NOD recipients. Diabetic incidence was monitored up to 7 days after transfer and pancreatic insulitis of four mice in each group was evaluated at 3 days after transfer. The severity of insulitis was assessed by using the scoring system as follows [13, 14]: 0) normal islets; 1) mononuclear cell infiltration in less than $25 \%$ of the islets; 2) $25-50 \%$ of the islet infiltrated; 3 ) over $50 \%$ infiltrated; 4) small retracted islets with few mononuclear cells.

Statistical analysis of diabetes incidence was determined with Fisher's exact method. Statistical analysis of insulitis score was made by the non-parametric Mann-Whitney U-test.

\section{Results}

Characteristics of CD 8 T-cell clone. Proliferative responses of CD8 T-cell clone (YNK1.3) to the islets from various strains of mice and insulinoma cell lines were determined by ${ }^{3} \mathrm{H}$-thymidine uptake (Fig. 1). YNK1.3 cells responded well to NOD islets, $\mathrm{BALB} / \mathrm{c}$ islets, and NOD-derived insulinoma MIN6$\mathrm{N} 8$ a with stimulation indices (mean cpm in the presence of antigen/mean cpm without antigen) over 15. However, this clone did not respond to NOD spleen cells, C57BL/6 islets, and B6-derived insulinoma MIN6. As previously reported [14], YNK1.3 cells did not exhibit any cytotoxic activity against MIN6 insulinoma cells derived from C57BL/6 mice $\left(\mathrm{H}-2^{\mathrm{b}}\right)$, but exhibited strong cytotoxicity to both MIN6N8 a and NIT-1 insulinoma cells derived from NOD mice $\left(\mathrm{H} 2-\mathrm{K}^{\mathrm{d}} \mathrm{D}^{\mathrm{b}}\right)$ in ${ }^{51} \mathrm{Cr}$ release assay. This cytotoxicity was completely inhibited by an anti- $\mathrm{K}^{\mathrm{d}} \mathrm{mAb}$ but not by anti-D ${ }^{\mathrm{b}} \mathrm{mAb}$. In addition, YNK1.3 cells did show prominent cytotoxicity against islet cells from NOD mice as well as NOD-derived insulinoma cell lines (data not shown). Furthermore, YNK1.3 cells did not exhibit any cytotoxic activity against other $\mathrm{H}-2 \mathrm{~K}^{\mathrm{d}}$-expressed cultured cell lines such as

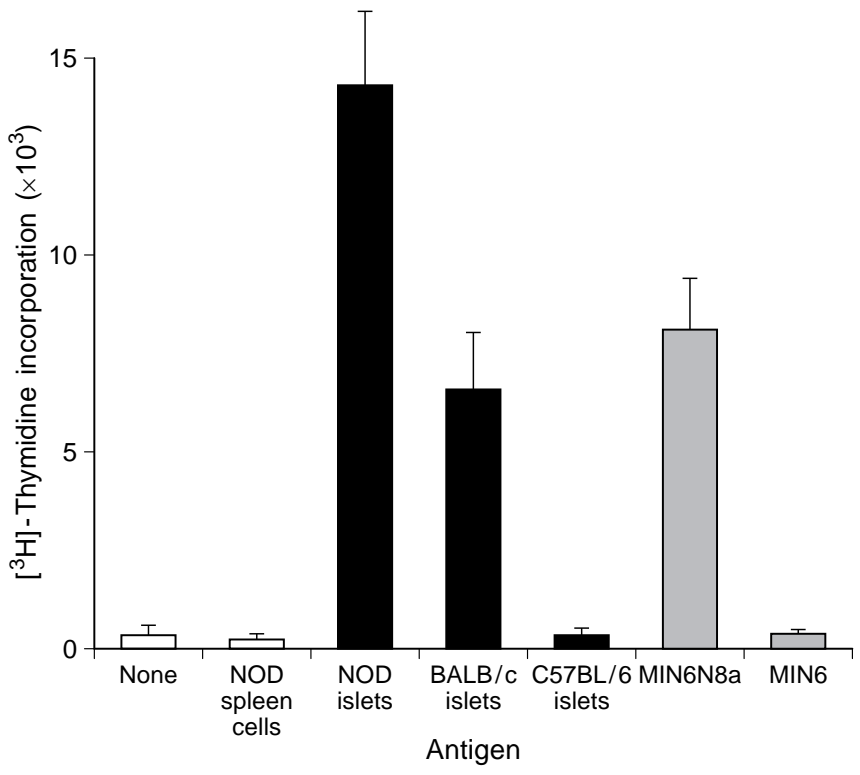

Fig. 1. Proliferative responses of CD8 T-cell clones (YNK1.3) to various antigens. Isolated islets from $\mathrm{NOD}\left(\mathrm{H}-2 \mathrm{~K}^{\mathrm{d}} \mathrm{D}^{\mathrm{b}}\right)$, $\mathrm{BALB} / \mathrm{c}\left(\mathrm{H}-2^{\mathrm{d}}\right)$, and $\mathrm{C} 57 \mathrm{BL} / 6\left(\mathrm{H}-2^{\mathrm{b}}\right)$ mice and murine insulinoma cell line, MIN6N8 a $\left(\mathrm{H}-2 \mathrm{~K}^{\mathrm{d}} \mathrm{D}^{\mathrm{b}}\right)$ and MIN6 $\left(\mathrm{H}-2^{\mathrm{b}}\right)$, were used as antigen. ${ }^{3} \mathrm{H}$-thymidine incorporation (cpm) into YNK1.3 cells by stimulation of these antigens was compared with that without antigen or by stimulation of NOD spleen cells. Data are expressed as the mean \pm SD of three different experiments

MOPC315 (plasmacytoma originated from BALB/c mice) and P815 cells (mastiocytoma from DBA/ 2 mice). YNK1.3 cells, therefore, exhibited $\mathrm{H}-2 \mathrm{~K}^{\mathrm{d}}$ restricted and islet-specific cytotoxic activity, and proliferated well in response to $\mathrm{H}-2 \mathrm{~K}^{\mathrm{d}}$-expressed islet and insulinoma cells.

Figure 2 demonstrates the expression of activation and adhesion molecules on YNK1.3 cells examined by flow cytometric analysis. YNK1.3 cells expressed the activation marker CD25 but not CD69 and CD28 on their cell surface. The cells also expressed the adhesion molecule CD54 (ICAM-1) but not $\alpha 4$ and $\beta 7$-integrins. Flow cytometric analysis showed that both YNK1.3 and YNK2.1 CD8 clones expressed TCR $\alpha \beta$ and $\mathrm{V} \beta 8$ (data not shown).

A doptive transfer of diabetes in NOD mice by CD 8 Tcell clones. To elucidate the pathogenic role of CD8 T cells in the NOD mouse, YNK1.3 cells were injected intraperitoneally into young NOD mice. When 1$2 \times 10^{7}$ cells were injected into 7 - or 10 -days-old female NOD mice, all recipients (16/16) became overtly diabetic within 4 days post-transfer. However, none of 14 recipients injected with $1-2 \times 10^{7}$ YNK1.3 cells at 14 days $(0 / 4), 21$ days $(0 / 5)$, and 28 days $(0 / 5)$ of age became diabetic at least 42 days after transfer. Smaller numbers of YNK1.3 cells $\left(2.5-5 \times 10^{6}\right)$ could not rapidly induce the disease in 7-day-old NOD mice, but over $80 \%(9 / 11)$ of recipients became 

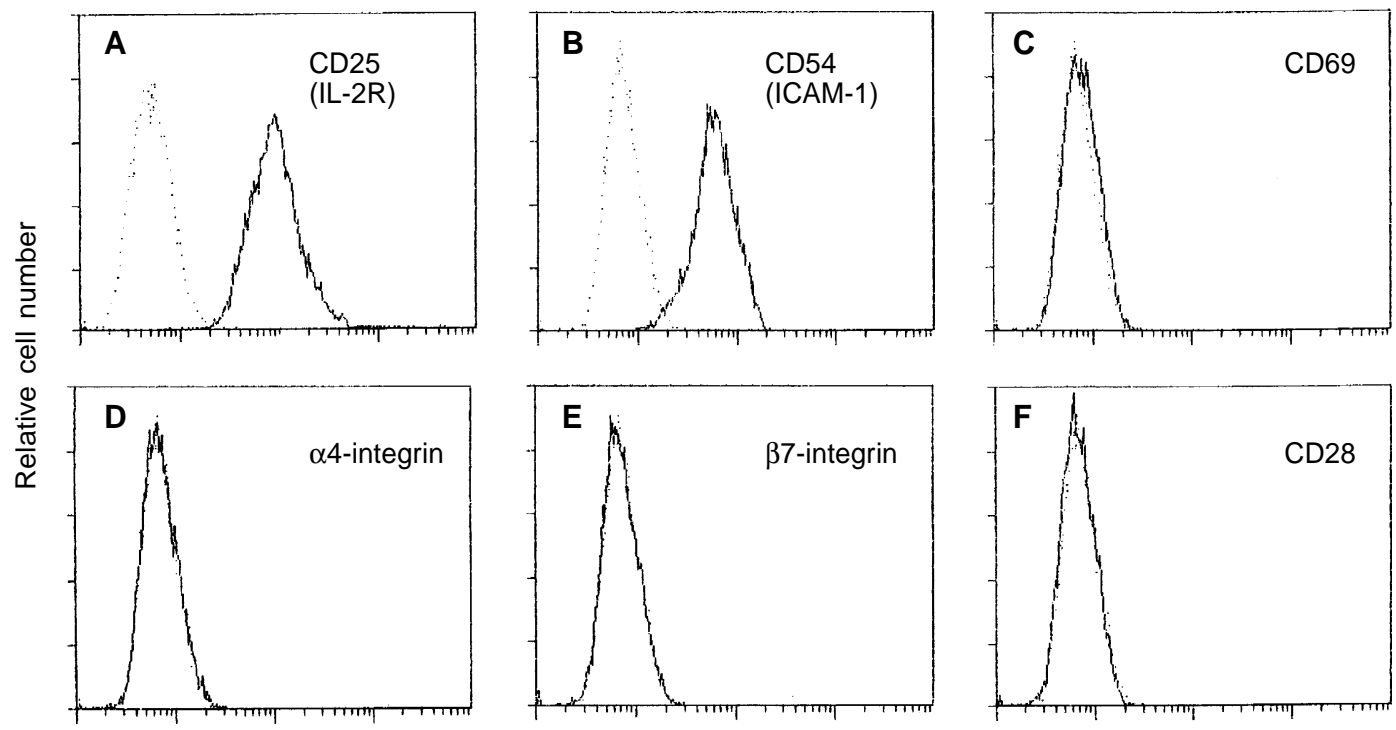

Log fluorescence intensity

Fig. 2A -F. Expression of activation and adhesion molecules on YNK1.3 cells. YNK1.3 cells were stained with mAb against CD25 (A), CD54 (B), CD69 (C), $\alpha 4$-integrin (D), $\beta 7$-integrin (E), and CD28 (F), and analysed by flow cytometry

Table 1. Adoptive transfer of diabetes in young NOD mice by CD8 T-cell clones

\begin{tabular}{|c|c|c|c|c|}
\hline \multicolumn{2}{|l|}{ Donor } & \multirow{2}{*}{$\begin{array}{l}\text { Recipient } \\
\text { Age (days) }\end{array}$} & \multicolumn{2}{|l|}{ Diabetes } \\
\hline Clone & $\begin{array}{l}\text { Number } \\
\text { of cells }\end{array}$ & & $\begin{array}{l}\text { Incidence } \\
(\%)\end{array}$ & $\begin{array}{l}\text { Duration } \\
\text { (days after } \\
\text { transfer) }\end{array}$ \\
\hline YNK 1.3 & $\begin{array}{r}1 \times 10^{6} \\
2.5 \times 10^{6} \\
5 \times 10^{6} \\
1 \times 10^{7} \\
2 \times 10^{7} \\
1 \times 10^{7} \\
1 \times 10^{7} \\
2 \times 10^{7} \\
2 \times 10^{7}\end{array}$ & $\begin{array}{r}7 \\
10 \\
14 \\
21 \\
28\end{array}$ & $\begin{array}{l}1 / 6(17) \\
3 / 4^{\mathrm{a}}(75) \\
6 / 7^{\mathrm{a}}(86) \\
7 / 7^{\mathrm{a}}(100) \\
\\
5 / 5^{\mathrm{a}}(100) \\
4 / 4^{\mathrm{a}}(100) \\
0 / 4(0) \\
0 / 5(0) \\
0 / 5(0)\end{array}$ & $\begin{array}{l}15 \\
14,33,34 \\
4,7,10,11, \\
12,23 \\
2,2,2,2,2, \\
3,3 \\
2,2,2,3,4 \\
2,2,3,4\end{array}$ \\
\hline YNK 2.1 & $1 \times 10^{7}$ & 7 & $0 / 6(0)$ & \\
\hline
\end{tabular}

Recipient NOD mice received a single injection of $1 \times 10^{6}$ $2 \times 10^{7}$ CD8 T-cell clones (YNK 1.3 or YNK 2.1) at the indicated age. Diabetes was defined as 2 consecutive days of hyperglycaemia (plasma glucose $>16.7 \mathrm{mmol} / \mathrm{l}$ ). Mice that did not develop overt diabetes were observed at least 42 days after transfer.

${ }^{a} p<0.05$ compared with diabetic incidence of YNK 2.1 (Fisher's exact method)

gradually diabetic during 6 weeks after transfer. However, only 1 of 6 NOD mice became diabetic when $1 \times 10^{6}$ YNK1.3 cells were administered at 7-daysold. The non-cytolytic CD8 T-cell clone (YNK2.1, $1 \times 10^{7}$ ) failed to induce diabetes in NOD mice even when administered at 7 days of age (Table 1).
In order to estimate the difference in diabetogenesis of the CD8 T-cell clone at the different ages of NOD mice, histological analysis was performed. Massive and diffuse infiltration of mononuclear cells into the islet was observed and some islets exhibited almost complete destruction in NOD mice which received $1 \times 10^{7}$ YNK1.3 cells at 7 days of age and killed at $36 \mathrm{~h}$ after transfer (Fig. 3A). In contrast, in the pancreas from NOD mice which received $2 \times 10^{7}$ YNK1.3 cells at 21 days of age, the infiltration of mononuclear cells was also found, but it was not significant and limited to the peripheral site of the islets (Fig. 3B).

To demonstrate that the islet-reactive CD8 T-cell clone itself infiltrated into the NOD islets directly after intraperitoneal administration, YNK1.3 cells were labelled with a fluorescent dye, $\mathrm{PKH} 2$, and $1 \times 10^{7}$ cells were injected into 7-day-old NOD mice. Fluorescent dye-labelled YNK1.3 cells accumulated in the islets and occupied the dominant population of infiltrating mononuclear cells at $36 \mathrm{~h}$ post-transfer (Fig. 3C). A few labelled cells were found in the spleen, but not in the liver and kidney (data not shown). These results suggest that CD8 T-cells in sufficient number have the ability to rapidly and specifically accumulate in the islets of NOD mice at 7-10days-old.

A doptive transfer of diabetes in various scid mice by CD 8 T-cell clone. To eliminate the influence of endogenous $\mathrm{T}$ cells in the recipient mice, various scid mice were used as recipients. Five of 9 NOD-scid mice became rapidly diabetic within 5 days after cell transfer, when they received $1-2 \times 10^{7}$ YNK1.3 cells at 7 days of age (Table 2). None of the 4 non-diabetic recipients became diabetic until 7 weeks of age. Histological examination demonstrated extensive and diffuse lymphocytic infiltration in the islets from 


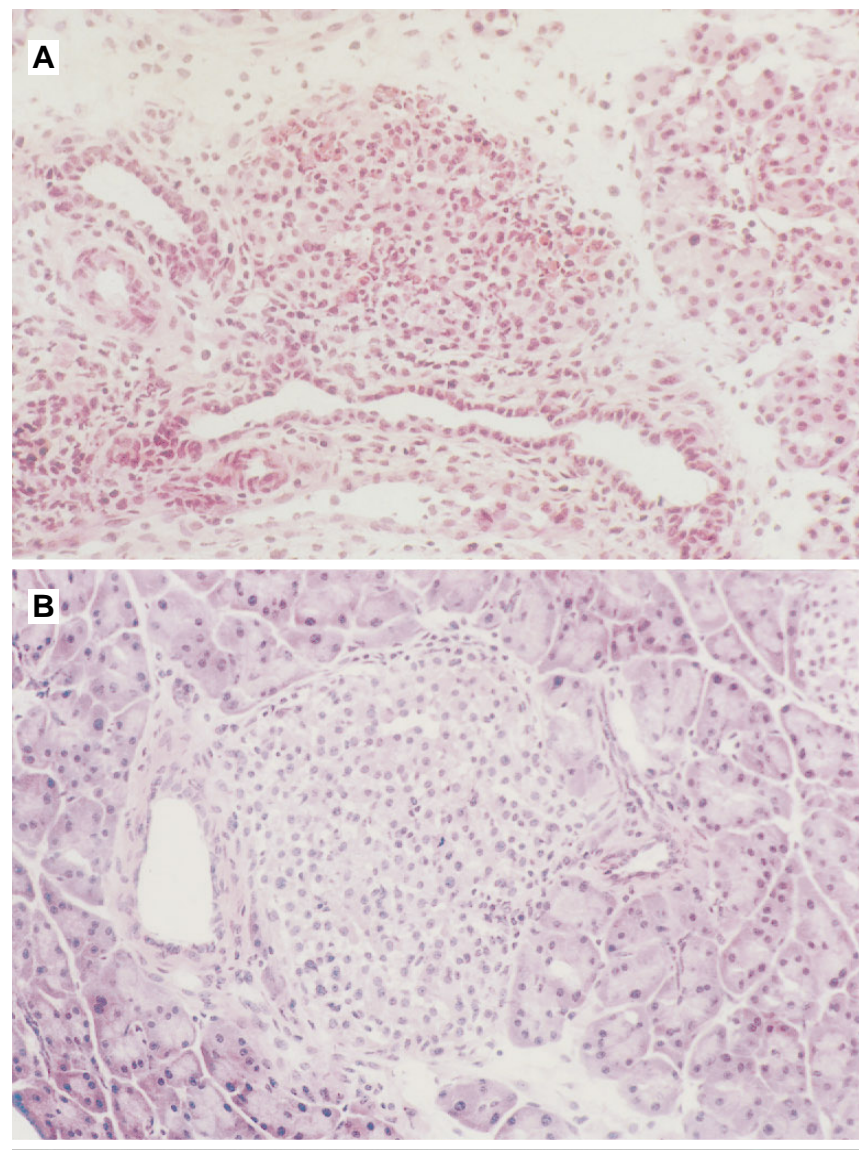

\section{C}

Fig. 3A - C. Photomicrographs of pancreatic islets after transfer of CD8 T-cell clone (YNK1.3) in NOD mice. (A) YNK1.3 cells $\left(1 \times 10^{7}\right)$ were injected into 7 -day-old NOD mice. (B) YNK1.3 cells $\left(2 \times 10^{7}\right)$ were injected into 21-day-old NOD mice. At $36 \mathrm{~h}$ after transfer, pancreata were removed and snap-frozen. Five $\mu \mathrm{m}$ of frozen sections were rendered to haematoxylin-eosin staining $(\times 200)$. (C) Fluorescent dye (PKH2)-labelled YNK1.3 cells $\left(1 \times 10^{7}\right)$ were injected into 7day-old NOD mice. At $36 \mathrm{~h}$ after transfer, pancreata were removed and frozen in OCT compound in nitrogen liquid. Five $\mu \mathrm{m}$ of frozen sections were mounted on albumin coated slides, dried in the dark, and then mounted with an antifade media. The slides were examined under fluorescence microscopy
Table 2. Adoptive transfer of diabetes in various scid mice by CD8 T-cell clone

\begin{tabular}{|c|c|c|c|c|}
\hline \multicolumn{2}{|l|}{ Recipient } & \multirow{2}{*}{$\begin{array}{l}\text { Number of } \\
\text { YNK } 1.3 \\
\text { cells }\end{array}$} & \multicolumn{2}{|l|}{ Diabetes } \\
\hline Mouse & $\begin{array}{l}\text { Age } \\
\text { (days) }\end{array}$ & & $\begin{array}{l}\text { Incidence } \\
(\%)\end{array}$ & $\begin{array}{l}\text { Duration } \\
\text { (days after } \\
\text { transfer) }\end{array}$ \\
\hline NOD-scid & $\begin{array}{r}7 \\
7 \\
7 \\
14 \\
21 \\
21\end{array}$ & $\begin{array}{l}5 \times 10^{6} \\
1 \times 10^{7} \\
2 \times 10^{7} \\
2 \times 10^{7} \\
2 \times 10^{7} \\
4 \times 10^{7}\end{array}$ & $\begin{array}{l}0 / 5(0) \\
3 / 5(60) \\
2 / 4(50) \\
1 / 4(25) \\
0 / 4(0) \\
0 / 4(0)\end{array}$ & $\begin{array}{l}2,4,4 \\
3,5 \\
6\end{array}$ \\
\hline BALB/c-scid & $\begin{array}{r}7 \\
14\end{array}$ & $\begin{array}{l}1 \times 10^{7} \\
1 \times 10^{7}\end{array}$ & $\begin{array}{l}3 / 4(75) \\
0 / 6(0)\end{array}$ & $2,3,5$ \\
\hline CB17-scid & 7 & $1 \times 10^{7}$ & $6 / 12(50)$ & $4,5,6,6,6,6$ \\
\hline C57BL/6-scid & 7 & $2 \times 10^{7}$ & $0 / 10(0)$ & \\
\hline
\end{tabular}

Recipient NOD-scid (H-2K $\left.{ }^{\mathrm{d}} \mathrm{D}^{\mathrm{b}}\right), \mathrm{BALB} / \mathrm{c}-\mathrm{scid}\left(\mathrm{H}-\mathrm{2}^{\mathrm{d}}\right), \mathrm{CB} 17$ scid $\left(\mathrm{H}-2^{\mathrm{d}}\right)$, and $\mathrm{C} 57 \mathrm{BL} / 6$-scid $\left(\mathrm{H}-2^{\mathrm{b}}\right)$ mice received a single injection of $5 \times 10^{6}-4 \times 10^{7} \mathrm{CD} 8 \mathrm{~T}$ cell clones (YNK 1.3) at the indicated age. Diabetes was defined as 2 consecutive days of hyperglycaemia (plasma glucose $>16.7 \mathrm{mmol} / \mathrm{l}$ ). Mice that did not develop overt diabetes were observed at least 42 days after transfer

diabetic NOD-scid recipients at $36 \mathrm{~h}$ after transfer (data not shown), as shown in NOD recipients. However, only 1 of the 12 NOD-scid mice that received $2-4 \times 10^{7}$ YNK1.3 cells became diabetic when the donor cells were administered after 14 days of age. In the pancreas from NOD-scid mice that received $2 \times 10^{7}$ YNK1.3 cells at 21 days of age, infiltration of mononuclear cells was not found (data not shown). Furthermore, in contrast to NOD mice as recipients, $5 \times 10^{6}$ YNK1.3 cells could not induce overt diabetes in 7-day-old NOD-scid mice (0/5) by 7 weeks of age.

Figure 4 summarizes the time course of diabetes induction in 7-day-old NOD and NOD-scid mice after administration of various numbers of YNK1.3 cells. The incidence of CD8 T-cell clone induced diabetes was clearly dependent on number of donor cells in NOD recipients. In addition, lower incidence and slightly delayed onset of diabetes were observed in NOD-scid recipients as compared to NOD recipients.

Table 2 also shows that YNK1.3 cells $\left(1-2 \times 10^{7}\right)$ could transfer diabetes in BALB/c-scid (3/4) and CB17-scid mice (6/12) when administered at 7 days of age, but not in C57BL/6-scid mice (0/10) at the same age. Again, $1 \times 10^{7}$ of this clone could not induce diabetes in 14-day-old BALB/c-scid mice (0/6) by 7 weeks of age. These results suggest that YNK1.3 cells have the ability to rapidly induce diabetes not only in NOD mice but also in scid mice matched for $\mathrm{H}-2 \mathrm{~K}^{\mathrm{d}}$.

E ffect of mA bs against adhesion molecules on adoptive transfer of diabetes. To elucidate the role of adhesion molecules in the migration of CD8 T-cell clones into pancreatic islets, antibodies against these 


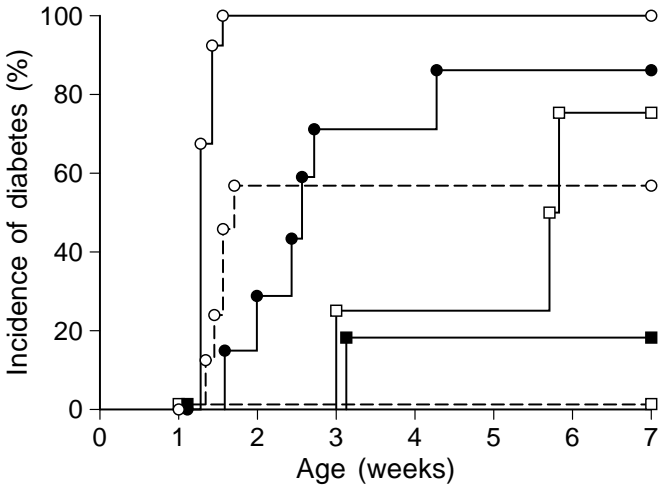

Fig. 4. Time course of diabetes induction in 7-day-old NOD and NOD-scid mice by various cell numbers of YNK1.3 cells. NOD mice received 1 or $2 \times 10^{7}(\mathrm{n}=12, \bigcirc-\bigcirc), 5 \times 10^{6}$ $\left(\mathrm{n}=7, \bigcirc-2.5 \times 10^{6}(\mathrm{n}=4, \square-\square)\right.$, and $1 \times 10^{6} \quad(\mathrm{n}=6$, - Y YNK1.3 cells at 7 days of age. NOD-scid mice received 1 or $2 \times 10^{7}(\mathrm{n}=9, \bigcirc \cdots \bigcirc)$ and $5 \times 10^{6} \quad(\mathrm{n}=5, \square \cdots \square)$ YNK1.3 cells at 7 days of age. Onset of diabetes was monitored by 2 consecutive days of hyperglycaemia (plasma glucose $>16.7 \mathrm{mmol} / \mathrm{l}$ ). The mice that did not develop overt diabetes were observed for at least 42 days after transfer

Table 3. Effect of mAb against adhesion molecules on CD8 Tcell clone-induced diabetes in NOD mice

\begin{tabular}{llll}
\hline mAb & $\begin{array}{l}\text { Transfer of } \\
\text { YNK 1.3 cells }\end{array}$ & $\begin{array}{l}\text { Incidence } \\
\text { of diabetes } \\
(\%)\end{array}$ & $\begin{array}{l}\text { Insulitis } \\
\text { score }\end{array}$ \\
\hline None & - & $0 / 10(0)$ & \\
$\begin{array}{l}\text { None } \\
\begin{array}{l}\text { Anti- } \alpha 4-\text { 4ntegrin } \\
\text { plus anti-VCAM-1 }\end{array}\end{array}$ & + & $9 / 10(90)$ & $3.2 \pm 0.6$ \\
$\begin{array}{l}\text { Anti-ICAM-1 } \\
\text { plus anti-LFA-1 }\end{array}$ & + & $5 / 6(83)$ & $2.9 \pm 0.7$ \\
\hline
\end{tabular}

Seven-day-old recipient NOD mice were injected intraperitoneally with $500 \mu \mathrm{g}$ of either R1-2 (anti- $\alpha 4$-integrin) and M/ K2 (anti-VCAM-1) or KAT-1(anti-ICAM-1) and KBA (antiLFA-1) mAbs at 1 day before transfer of YNK 1.3 cells. YNK 1.3 cells $\left(1 \times 10^{7}\right)$ were incubated with $10 \mu \mathrm{g} / \mathrm{ml}$ relevant $\mathrm{mAb}$ for $30 \mathrm{~min}$ at $4^{\circ} \mathrm{C}$ and then transferred into corresponding $\mathrm{mAb}$-pretreated NOD recipients. Diabetic incidence was monitored up to 7 days after transfer and the degree of pancreatic insulitis of four mice in each group was evaluated at 3 days after transfer. Insulitis score was presented as the mean \pm SD. No difference was observed between insulitis score of each group (Mann-Whitney U-test).

${ }^{a} p<0.05$ compared with diabetes incidence of YNK 1.3-transferred mice without antibody (Fisher's exact method)

molecules were administered into 7-day-old recipient NOD mice before injection of YNK1.3 cells (Table 3). When mAbs against $\alpha 4$-integrin and VCAM1 were pretreated in recipient mice, both the severity of insulitis and the incidence of diabetes were not decreased. On the other hand, treatment of antiICAM-1 and anti-LFA-1 antibodies did not prevent a severe infiltration of YNK1.3 cells to pancreatic islets but decreased the incidence of diabetes. These results suggest that functional molecules related to transendothelial migration of lymphocytes are not involved in the infiltration of CD8 T-cell clones into pancreatic islets in 7-day-old NOD mice and that ICAM-1/LFA-1 interaction may contribute to the destruction of beta cells after transfer of CD8 T cells.

\section{Discussion}

In the present study, the CD8 T-cell clone, YNK1.3, which is restricted by $\mathrm{H}-2 \mathrm{~K}^{\mathrm{d}}$, was able to rapidly transfer overt diabetes not only in NOD mice but also in NOD-scid, BALB/c-scid, and CB17-scid mice. Since YNK1.3 cells in sufficient number transfered diabetes both in unmanipulated NOD mice within 4 days of cell transfer and in MHC class I-compatible scid mice that lacked functional endogenous lymphocytes, it is unlikely that CD4 T cells: 1) are activated by APC presenting specific autoantigens released from islet cells damaged by CD8 T cell clones; 2 ) produce IL-2 and interferon (IFN)- $\gamma$, and; 3 ) activate and recruit more CD8 T-cells. This is supported by the fact that fluorescent dye-labelled CD8 T cells extensively accumulated in the islets and appeared to be mainly composed of islet-infiltrating mononuclear cells. However, in comparison with a study using NOD mice as recipients, lower diabetes incidence and slightly delayed diabetes onset as observed in $\mathrm{H}-2 \mathrm{~K}^{\mathrm{d}}$ matched scid mice might indicate the significant contribution of endogenous Tand B cells especially CD4 T cells to beta-cell destruction even in such a short period. As previously reported, NOD islet-derived CD8 T-cell clones stimulated with NOD islet cells alone could transfer diabetes only in the presence of CD4 T cells [10], whereas the present study has shown that the CD8 T-cell clone (YNK1.3) generated by the stimulation with NOD islet cells and MMC-treated NOD spleen cells (acting as APC) rapidly induced diabetes in NOD mice in the absence of CD4 T cells. Recently, Wong et al. reported that when islet-specific CD8 Tcell clones derived from islet-infiltrating cells of 7week-old NOD mice were optimally activated in the presence of the co-stimulator B7-1 expressed on pancreatic beta cells, these CD8 T-cell clones could very rapidly cause diabetes in irradiated female NOD, NOD-scid and CB17-scid mice in the absence of CD4 T cells [9]. Therefore, if diabetes transfer must be successfully achieved by CD8 T cells alone, enough optimally activated islet-specific CD8 T cells must be administered. If neither islet-specific CD8 T cells were optimally activated nor enough numbers of the cells to induce the rapid destruction of beta cells and overt diabetes, migrated to the islet, CD8 T cells could not expand and be maintained in the absence of CD4 $\mathrm{T}$ cells. This is supported by the finding that $5 \times 10^{6}$ YNK1.3 cells could induce diabetes to reach over $80 \%$ by 7 weeks of age in 7-day-old NOD mice, whereas the same number of YNK1.3 cells could not 
induce diabetes in 7-day-old NOD-scid mice even during the long-term observation period. Furthermore, immunohistological study revealed that in addition to CD8 T cells, CD4 T cells also accumulated in the islet lesion of recipient NOD mice at 4-7 days after transfer of $5 \times 10^{6}$ YNK1.3 cells. At 20 days after transfer, dominant CD4 T cells and a smaller number of CD8 T cells were observed as seen in adult NOD inflammatory islets. When anti-CD4 $\mathrm{mAb}$ was administered to these recipient NOD mice before transfer, neither insulitis nor overt diabetes was observed (data not shown). In the natural course of insulitis and diabetes in NOD mice, it might be suggested that a few autoreactive CD8 T cells initially destroy a part of the beta cells, resulting in the release of beta-cell specific autoantigens. These autoantigens are processed by regional macrophages and/or dendritic cells in the islets and presented to CD4 Th1 cells. The autoreactive CD4 Th1 cells exert a direct effect on betacell destruction by inflammatory cytokines to induce tissue damage, and recruit and activate direct effector cells including CD8 T cells and macrophages.

A unique phenomenon observed in the present study is the age-dependent susceptibility of CD8 Tcell clone to islet cells. YNK1.3 rapidly induced diabetes not only in 7-10-day-old NOD mice but also in 7-day-old NOD-scid, BALB/c-scid and CB17-scid mice. However, these strains of mice at 14 days of age or older were highly resistant to CD8 T-cell clone induced diabetes. Similar findings were reported by Bendelac et al. [1]; the susceptibility of NOD recipients to diabetes transfer by bulk splenic $\mathrm{T}$ cells from NOD donors was limited to the first week of life and declined after 3 weeks of age. Peterson et al. [15] also reported that islet-specific CD4 T-cell clones were diabetogenic in 8-18-day-old NOD mice, while NOD mice, 19 days or older, were completely resistant to CD4 T-cell-clone induced diabetes. In contrast to CD4 T-cell clones, there are few reports of CD8 Tcell clones generated from NOD mice, since CD8 Tcell clones are difficult to isolate and maintain. Therefore, there are no reports on the effect of recipient's age on the induction of diabetes by islet-specific CD8 T-cell clones. The reason for the age-dependent susceptibility of recipients to the CD8 T-cell-induced disease may be related to both activation status of donor cells and pancreatic architecture or unique immune status of very young recipients. Activated status of CD8 T cells could be important for the migration into pancreatic islets and the destruction of beta cells. Recent reports demonstrate that lymphocytic inflammation is mediated largely by LFA-1/ICAM-1 and very late antigen-4 (VLA-4; $\alpha 4 / \beta 1$-integrin)/ VCAM-1 interactions [16, 17]. Significant contribution of these two pairs of adhesion molecules to autoimmune inflammation of pancreatic islets in NOD mice was also reported [14, 18-22]. YNK1.3 cells expressed the activation marker CD25 and the adhesion molecule LFA-1, ICAM-1, but not CD28, CD69 and $\alpha 4$-integrin. The loss of expression of $\alpha 4$-integrin on our CD8 T-cell clone may account for the age-dependent susceptibility to islet cells. Wong et al. [9] reported that their islet-specific CD8 T-cell clones activated optimally by B7-1-expressed islet cells rapidly induced diabetes in irradiated 7-week-old female NOD, 2-3-week-old female NOD-scid and CB17scid mice. Both their CD28+ ${ }^{+}$CD 8 clones and our $\mathrm{CD} 28^{-} \mathrm{CD} 8$ clones transfered diabetes in the absence of CD4 T cells. Different from their CD8 clones, those generated in the present study could not transfer diabetes into irradiated 7-week-old NOD mice (data not shown) and 3-week-old NOD scid mice. Activated status of CD8 clones might determine the ability to migrate into the pancreatic islets. Their CD8 T-cell clones expressed not only ICAM-1 but also $\alpha 4$-integrin. Therefore, a possible migration of our CD8 T-cell clone into the islets not in 14-day-old or older but in 7-10-day-old NOD mice, suggests that LFA-1/ICAM-1 interaction rather than VLA-4/ VCAM-1 pathway may be more important in the migration of CD8 $\mathrm{T}$ cells to very young NOD islets. However, not only anti- $\alpha 4$-integrin/VCAM-1 mAb but also anti-LFA-1/ICAM-1 mAb pretreatment in 7-day-old recipients could not block the pancreatic islet infiltration of YNK1.3 cells. These results suggest that functional transendothelial migration, in which LFA-1/ICAM- 1 and $\alpha 4$-integrin/VCAM- 1 pathways are involved, may not contribute to CD8 T-cell infiltration to pancreatic islets in very young mice.

Unique pancreatic architecture and islet neogenesis of very young mice may contribute to more easy trafficking of activated CD8 T cells to the islets than adult mice. The pancreas of very young mice around 1-2 week of age shows several distinctive features as compared with adults. A smaller size of islets and a loose arrangement of exocrine and endocrine glands were observed in very young mice (our histological observation). In addition, it has been recently reported that the microvasculature of target tissues expresses antigens that strongly affect cytotoxic $\mathrm{T}$ lymphocyte (CTL) access to tissue antigen. The vasculature displaying a continuous endothelium and basement membrane constitutes an extremely effective barrier that precludes CTL access to tissue antigen [23]. A recent study revealed that CD8 CTL clones from NOD mice could infiltrate into NOD islet grafts under the renal capsule within 1 week after transplantation, but not thereafter, indicating that the fenestrated barrier on capillary endothelia of islet grafts, prior to establishing complete revascularization, might result in the migration of CTL [24]. It may be speculated that the islet-specific CD8 CTL clone could be rapidly accessible to pancreatic islets of mice before 14 days of age when the epithelial tissue still does not contain intact microvascular endothelium in the process of maturation. Once a continuous layer of 
endothelial cells is etablished in the pancreas of mice older than 14 days, the vascular barrier must be breached by other factors. Before CD8 CTL gain access to islet beta cells, inflammatory changes probably mediated by islet-specific CD4 T cells may be necessary. In addition, the study in differentiation and development of the pancreas in mice revealed that the concentration of $\gamma$-aminobutyric acid (GABA) in the pancreas reached a peak on postnatal day 7 and then decreased to the adult level on postnatal day 45 . The large perinatal GABA concentration in the pancreas correlates with the time span during which islet neogenesis is most active $[25,26]$. This finding may also be related to favourable CD8 T-cell access to islet cells in mice around 7 days of age.

Recent studies suggest that CD8 T cells play an important role in the initiation of autoimmune insulitis in NOD mice [27]. Initial cells infiltrating pancreatic islets of NOD mice were reported to consist of $\mathrm{CD} 8 \mathrm{~T}$ cells and macrophages [28]. $\beta 2$-microglobulin-deficient NOD mice fail to develop insulitis and overt diabetes, whereas splenic $\mathrm{T}$ cells from diabetic NOD mice can transfer insulitis and diabetes to these $\beta 2$-microglobulin-deficient NOD mice [7, 8]. Our recent studies revealed that CD8 CTL established from NOD islets showed a strong LFA-1/ICAM-1dependent cytotoxicity against islet cells [14], and that short-term blockade of the LFA-1/ICAM-1 pathway in very young NOD mice resulted in the longlasting complete protection of insulitis and spontaneous diabetes [22]. Prevention of CD8 CTL-induced diabetes by anti-LFA-1/ICAM-1 mAbs treatment (Table 3) may account for the inhibition of direct islet-cell destruction by CD8 CTL, resulting in the abrogation of the subsequent autoimmune responses against pancreatic islets. Further study is necessary for evaluating the initial immune responses against islet cells in NOD mice.

A cknowledgements. This work was supported in part by a Grant-in-aid for Scientific Research from the Japanese Ministry of Education, Science and Culture.

We gratefully acknowledge Dr. J. Miyazaki, Department of Disease-Related Gene Regulation Research, Faculty of Medicine, University of Tokyo, for insulinoma cell lines.

\section{References}

1. Bendelac A, Carnaud C, Boitard C, Bach JF (1987) Syngeneic transfer of auto immune diabetes from diabetic NOD mice to healthy neonates requirement for both $\mathrm{L}_{3} \mathrm{~T}^{+}$and Lyt-2 + T cells. J Exp Med 166: 823-832

2. Miller BJ, Appel MC, O’Neil JJ, Wicker LS (1988) Both the LYT $-2^{+}$and $\mathrm{L} 3 \mathrm{~T} 4{ }^{+} \mathrm{T}$ cell subsets are required for the transfer of diabetes in nonobese diabetic mice. J Immunol 140: $52-58$

3. Shimizu J, Kanagawa O, Unanue ER (1993) Presentation of $\beta$-cell antigens to CD4 and CD8 T cells of non-obese diabetic mice. J Immunol 151: 1723-1730
4. Haskins K, McDuffie M (1990) Acceleration of diabetes in young NOD mice with a $\mathrm{CD}^{4}{ }^{+}$islet-specific $\mathrm{T}$ cell clone. Science 249: 1433-1436

5. Peterson JD, Pike B, McDuffie M, Haskins K (1994) Isletspecific $\mathrm{T}$ cell clones transfer diabetes to nonobese diabetic (NOD) F1 mice. J Immunol 153: 2800-2806

6. Prochazka M, Gaskins H, Shultz L, Leiter E (1992) The nonobese diabetic scid mouse model for spontaneous thymomagenesis associated with immunodeficiency. Proc Natl Acad Sci USA 89: 3290-3294

7. Wicker LS, Leiter EH, Todd JA et al. (1994) $\beta 2$-microglobulin-deficient NOD mice do not develop insulitis or diabetes. Diabetes 43: 500-504

8. Serreze DV, Leiter EH, Christianson GJ, Greiner D, Roopenian DC (1994) Major histocompatibility complex class I-deficient NOD-B2 ${ }^{\text {null }}$ mice are diabetes and insulitis resistant. Diabetes 43: 505-509

9. Wong FS, Visintin I, Wen L, Flavell RA, Janeway CA Jr (1996) CD8 T cell clones from young nonobese diabetic (NOD) islets can transfer rapid onset of diabetes in NOD mice in the absence of CD4 cells. J Exp Med 183: 67-76

10. Nagata M, Santamaria P, Kawamura T, Utsugi T, Yoon JW (1994) Evidence for the role of CD8 cytotoxic T cells in the destruction of pancreatic $\beta$ cells in nonobese diabetic mice. J Immunol 152: 2042-2050

11. Seko Y, Matsuda H, Kato K et al. (1993) Expression of intercellular adhesion molecule-1 in murine hearts with acute myocarditis caused by coxsackievirus B3. J Clin Invest 91: $1327-1336$

12. Horan PK, Melnicoff MJ, Jensen BD, Slezak SE (1990) Fluorescent cell labeling for in vivo and in vitro cell tracking. Methods Cell Biol 33: 469-490

13. Tsukamoto K, Yokono K, Amano K et al. (1995) Administration of monoclonal antibodies against vascular cell adhesion molecule-1/very late antigen-4 abrogates predisposing autoimmune diabetes in NOD mice. Cell Immunol 165: 193-201

14. Yagi N, Yokono K, Amano K et al. (1995) Expression of intercellular adhesion molecule 1 on pancreatic $\beta$-cells accelerates $\beta$-cell destruction by cytotoxic T-cells in murine autoimmune diabetes. Diabetes 44: 744-752

15. Peterson JD, Pike B, Dallas-Pedretti A, Haskins K (1995) Induction of diabetes with islet-specific T-cell clones is age dependent. Immunology 85: 455-460

16. Springer TA (1990) Adhesion receptors of the immune system. Nature 346: 425-434

17. Issekutz TB (1991) Inhibition of in vivo lymphocyte migration to inflammation and homing to lymphoid tissues by the TA-2 monoclonal antibody: a likely role for VLA-4 in vivo. J Immunol 147: 4178-4184

18. Hanninen A, Taylor C, Streeter PR et al. (1993) Vascular addressins are induced on islet vessels during insulitis in nonobese diabetic mice and are involved in lymphoid cell binding to islet endothelium. J Clin Invest 92: 2509-2515

19. Yang XD, Karin N, Tisch R, Steinman L, Mcdevitt HO (1993) Inhibition of insulitis and prevention of diabetes in nonobese diabetic mice by blocking L-selectin and very late antigen 4 adhesion receptors. Proc Natl Acad Sci USA 90: 10494-10498

20. Burkly LC, Jakubowsky A, Hattori M (1994) Protection against adoptive transfer of autoimmune diabetes mediated through very late antigen-4 integrin. Diabetes 43: 529534

21. Hasegawa Y, Yokono K, Taki T et al. (1994) Prevention of autoimmune insulin-dependent diabetes in NOD mice by anti-LFA-1 and anti-ICAM-1 monoclonal antibodies. Int Immunol 6: 831-638 
22. Moriyama H, Yokono K, Amano K et al. (1996) Induction of tolerance in murine autoimmune diabetes by transient blockade of leukocyte function-associated antigen-1/intercellular adhesion molecule-1 pathway. J Immunol 157: 3737-3743

23. Ando K, Guidotti LUG, Corny A, Ishikawa T, Chaucer TV (1994) CTL access to tissue antigen is restricted in vivo. J Immunol 153: 482-488

24. Utsugi T, Yoon JW, Park BJ, Imamura M, Averill N, Kawazu S, Santamaria P (1996) Major histocompatibility complex class I-restricted infiltration and destruction of pancreatic islets by NOD mouse-derived beta-cell cytotoxic $\mathrm{CD}^{+}{ }^{+}$T-cell clones in vivo. Diabetes. 45: 1121-1131

25. Julienne P, Remacle C, Janssens de Varebeke P, Pulse G, Hot JJ (1987) GABA content and localization of high- affinity GABA uptake during the development of the rat pancreas. Cell Mol Biol 33: 573-585

26. Githens S (1993) Differentiation and development of the pancreas in animals. In: Go VIM, Dimmer EN, Gardner JD, Lebenthal E, Refer HA, Schick GA (eds) The pancreas: biology, pathology, and disease. Raven Press, New York, pp 21-55

27. Wang B, Gonzalez A, Benoist C, Mathis D (1996) The role of $\mathrm{CD}^{+} \mathrm{T}$ cells in the initiation of insulin-dependent diabetes mellitus. Eur J Immunol 26: 1762-1769

28. Jarpe AJ, Hickman MR, Anderson JT, Winter WE, Peck AB (1990) Flow cytometric enumeration of mononuclear cell populations infiltrating the islets of Langerhans in prediabetic NOD mice: development of a model of autoimmune insulitis for type I diabetes. Reg Immunol 3: 305-317 